OPEN ACCESS

Edited by:

Egidio D'Angelo,

University of Pavia, Italy

Reviewed by:

Ping Liu,

University of Connecticut Health

Center, USA

Sandra Henriques Vaz,

Universidade de Lisboa, Portugal

*Correspondence:

Christian Giaume

christian.giaume@college-de-france.fr

Received: 28 September 2015

Accepted: 09 December 2015

Published: 07 January 2016

Citation:

Jeanson T, Pondaven A, Ezan $P$,

Mouthon F, Charvériat $M$ and Giaume C (2016)

Antidepressants Impact Connexin 43

Channel Functions in Astrocytes.

Front. Cell. Neurosci. 9:495.

doi: 10.3389/fncel.2015.00495

\section{Antidepressants Impact Connexin 43 Channel Functions in Astrocytes}

\author{
Tiffany Jeanson 1,2,3,4, Audrey Pondaven 1,2,3, Pascal Ezan ${ }^{1,2,3}$, Franck Mouthon ${ }^{4}$, \\ Mathieu Charvériat ${ }^{4}$ and Christian Giaume ${ }^{1,2,3 *}$
}

${ }^{1}$ Collège de France, Center for Interdisciplinary Research in Biology/Centre National de la Recherche Scientifique, Unité Mixte de Recherche 7241/Institut National de la Santé et de la Recherche Médicale U1050, Paris, France, ${ }^{2}$ University Pierre et Marie Curie, Paris, France, ${ }^{3}$ MemoLife Laboratory of Excellence and Paris Science Lettre Research University, Paris, France, ${ }^{4}$ Theranexus, Lyon, France

Glial cells, and in particular astrocytes, are crucial to maintain neuronal microenvironment by regulating energy metabolism, neurotransmitter uptake, gliotransmission, and synaptic development. Moreover, a typical feature of astrocytes is their high expression level of connexins, a family of membrane proteins that form gap junction channels allowing intercellular exchanges and hemichannels that provide release and uptake pathways for neuroactive molecules. Interestingly, several studies have revealed unexpected changes in astrocytes from depressive patients and rodent models of depressive-like behavior. Moreover, changes in the expression level of the astroglial connexin 43 (Cx43) have been reported in a depressive context. On the other hand, antidepressive drugs have also been shown to impact the expression of this connexin in astrocytes. However, so far there is little information concerning the functional consequence of these changes, i.e., the status of gap junctional communication and hemichannel activity in astrocytes exposed to antidepressants. In the present work we focused our attention on the action of seven antidepressants from four different therapeutic classes and tested their effects on Cx43 expression and on the two connexin-based channels functions studied in cultured astrocytes. We here report that when used at non-toxic and clinically relevant concentrations they have no effects on Cx43 expression but differential effects on Cx43 gap junction channels. Moreover, all tested antidepressants inhibit Cx43 hemichannel with different efficiency depending on their therapeutic classe. By studying the impact of antidepressants on the functional status of astroglial connexin channels, contributing to dynamic neuroglial interactions, our observations should help to better understand the mechanism by which these drugs provide their effect in the brain.

Keywords: gap Junctions, hemichannels, glial cells, depression, inflammation

\section{INTRODUCTION}

During the two last decades, a major step in the understanding of brain functions and dysfunctions has been to consider that not only neurons are at the center of these processes but that also their glial environment is actively involved. This statement is particularly true for astrocytes, a major glial cell population that establishes tight morphological and functional interactions with neurons (Halassa and Haydon, 2010; Verkhratsky et al., 2012) leading to the concept of the "tripartite 
synapse" (see Araque et al., 1999; Pérez-Alvarez and Araque, 2013). In brain pathologies and mental illness this partnership is impaired, contributing to severe neuronal defects and even in certain cases leading to neuronal death (Giaume et al., 2007; Bennett et al., 2012; Parpura et al., 2012). Such alterations in neuroglial interaction start to be investigated in order to identify and develop alternative therapeutic approaches that target astrocytes instead of solely neurons (Colangelo et al., 2014; Lundgaard et al., 2014; Vardjan et al., 2015). Following this strategy, the objective is to act on a specific astroglial molecular constituent known to regulate neuronal activity and/or survival. Based on these requirements astroglial connexins (Cxs), a family of membrane proteins, may be considered as a good candidate. Indeed, Cxs are highly expressed in astrocytes compared to all other brain cell populations (see Ransom and Giaume, 2013), including neurons, and they have been reported to interplay with synaptic activity and plasticity (Pannasch et al., 2011), animal behavior (Stehberg et al., 2012), and neuronal survival (Froger et al., 2010; FreitasAndrade and Naus, 2015). Besides, the expression and function of astroglial Cxs are affected in neurodegenerative diseases (Kawasaki et al., 2009; Koulakoff et al., 2012; Takeuchi and Suzumura, 2014), ischemia and stroke (Orellana et al., 2014), epilepsy (Mylvaganam et al., 2014), demyelinating diseases (Cotrina and Nedergaard, 2012) and cancer (Naus and Laird, 2010). Much less is known about the status, i.e., expression and function, of Cxs in astrocytes in non-neurodegenerative mood disorders such as depression, while those pathologies are associated to a reduction in the number of astrocytes and a decrease in GFAP immunoreactivity (see Rajkowska and Stockmeier, 2013).

Connexins are the molecular constituents of gap junctions that are membrane specializations consisting of dense aggregates of large pore channels formed by two paired hexamers of Cxs. These gap junction channels extend from one cell into an adjacent cell and mediate a unique direct cytoplasm-to-cytoplasm communication. These channels are poorly selective for ions and for small molecular weight signaling molecules, thus they allow extensive ionic and biochemical exchanges between cells (Harris, 2007). In astrocytes, gap junction channels provide the basis for ionic homeostasis, particularly for potassium buffering and intercellular calcium signaling. They are also involved in biochemical and metabolic coupling (see Ransom and Giaume, 2013). Under certain conditions Cxs can also operate as half of a gap junction channel, named "hemichannel," representing another functional state that provides a pathway suitable for autocrine as well as paracrine interactions in the brain. In astrocytes, connexin hemichannels are permeable to ions and are involved in the release of gliotransmitters such as ATP and glutamate (Ye et al., 2003; Kang et al., 2008; Abudara et al., 2015), the uptake of glucose (Retamal et al., 2007) and the efflux of glutathione (Rana and Dringen, 2007; Ye et al., 2015). In astrocytes two major Cxs have been identified, $\mathrm{Cx} 43$ and $\mathrm{Cx} 30$, which are not expressed in other brain cell types and are characterized by different developmental and regional patterns of expression (Nagy et al., 2004). Both Cxs contribute to gap junctional communication but so far only hemichannels made by $\mathrm{Cx} 43$ have been reported to be functional in astrocytes (see Giaume et al., 2013).

The information concerning astroglial Cxs and depression is based on two kinds of observations available from the literature. Firstly, those that report changes in the expression of astroglial Cxs from depressive patients, persons having committed suicide or from animal models of depression. Indeed, a Canadian study of postmortem generated microarray data suicide completers indicated that the expression level of $\mathrm{Cx} 43$ and $\mathrm{Cx} 30$ is reduced in dorsal lateral prefrontal cortex (Ernst et al., 2011) and in the locus coeruleus (Bernard et al., 2011). In addition, a recent study has reported that the expression of $\mathrm{Cx} 43$ is reduced in postmortem brains from patients suffering from major depressive disorder or comorbid depression relative to healthy subjects (Miguel-Hidalgo et al., 2014). Also, Sun et al. (2012) have reported a decrease in diffusion of gap junction channel-permeable dye and expression of $\mathrm{Cx} 43$ in the prefrontal cortex in rats subjected to chronic unpredictable stress. Secondly, on the other side treatment with antidepressants also results in changes in the expression level of $\mathrm{Cx} 43$ in astrocytes as indicated in Table 1. Five antidepressants, from three different therapeutic classes, have been tested in cellular and animal models; results indicate that 24-48 h treatment induces an increase in $\mathrm{Cx} 43$ expression at mRNA and/or protein levels. This is particularly the case for fluoxetine that has been tested in several models (Fatemi et al., 2008; Mostafavi et al., 2008; Sun et al., 2012). However, there is little information about the effect of these drugs on the functional status of gap junctional communication and none about hemichannel activity. So far based on this literature it is tempting to deduce and summarize that depressive brains show a down-regulation of $\mathrm{Cx} 43$ while antidepressant treatments favor its up-regulation (see Rajkowska and Stockmeier, 2013). Nevertheless, an important clue concerning Cxs is to identify the functional consequences of these treatments on $\mathrm{Cx} 43$ based channels since changes in level of expression can have unpredictable consequences on their function. In order to address this question we have carried out a systematic test of seven antidepressants on gap junctional communication and hemichannel activity in primary cultures of astrocytes, known to express only Cx43 (Dermietzel et al., 1991; Giaume et al., 1991; Koulakoff et al., 2008). The present study indicates that when used at a non-toxic and clinically relevant concentration they have differential effects on both channel functions leading to a more complicated global view of their action on intercellular communication mediated by $\mathrm{Cx} 43$ in astrocytes.

\section{MATERIALS AND METHODS}

All experiments were performed according to the European Community Council Directives of 2010/63/UE and all efforts were made to minimize the number of animals. This study was carried out in accordance with the recommendations of the Ethic Committee 59, Paris, France and received the approval of the 
TABLE 1 | Summary table of the effects of antidepressants on Cx43 expression and gap junctional function in astrocytes.

\begin{tabular}{|c|c|c|c|c|c|c|}
\hline Antidepressant & Class & Effect on Cx43 expression & $\begin{array}{l}\text { Effect on } \\
\text { Cx43 function }\end{array}$ & Model & Treatment (dose and time) & Reference \\
\hline Amitriptyline & TCA & Increase (mRNA, protein) & $\begin{array}{l}\text { Increase } \\
\text { (gap junction) }\end{array}$ & $\begin{array}{l}\text { Primary cultures rat } \\
\text { cortical astrocytes }\end{array}$ & $25 \mu \mathrm{M}, 48 \mathrm{~h}$ & Morioka et al., 2014 \\
\hline Clomipramine & TCA & Increase (protein) & NT & $\begin{array}{l}\text { Primary culture rat } \\
\text { cortical astrocytes }\end{array}$ & $10 \mu \mathrm{M}, 48 \mathrm{~h}$ & Morioka et al., 2014 \\
\hline Fluoxetine & SSRI & Increase (protein) & NT & $\begin{array}{l}\text { Rat in vivo } \\
\text { Prefrontal cortex }\end{array}$ & 20 mg/kg i.p. for 21 days & Fatemi et al., 2008 \\
\hline Fluoxetine & SSRI & Increase (mRNA, protein) & NT & $\begin{array}{l}\text { Human astrocytoma } \\
\text { cell line }\end{array}$ & $10,20 \mu \mathrm{g} / \mathrm{ml} 24 \mathrm{~h}$ & Mostafavi et al., 2008 \\
\hline Fluoxetine & SSRI & Increase (protein) & $\begin{array}{l}\text { No effect } \\
\text { (gap junction) }\end{array}$ & $\begin{array}{l}\text { Rat in vivo } \\
\text { Prefrontal cortex }\end{array}$ & $10 \mathrm{mg} / \mathrm{kg} 21$ days & Sun et al., 2012 \\
\hline Duloxetine & SNRI & Increase (mRNA, protein) & $\begin{array}{l}\text { No effect } \\
\text { (gap junction) }\end{array}$ & $\begin{array}{l}\text { Rat in vivo } \\
\text { Prefrontal cortex }\end{array}$ & $10 \mathrm{mg} / \mathrm{kg} 21$ days & Sun et al., 2012 \\
\hline Fluvoxamine & SSRI & Increase (protein) & NT & $\begin{array}{l}\text { Primary cultures rat } \\
\text { cortical astrocytes }\end{array}$ & $25 \mu \mathrm{M} 48 \mathrm{~h}$ & Morioka et al., 2014 \\
\hline
\end{tabular}

Scientific Committee of the animal facilities of the Collège de France.

\section{Cortical Astrocyte Cultures}

Primary astrocyte cultures were prepared from the cortex of newborn (1-2 days) OF1 mice as previously described (Meme et al., 2006). For western blot and scrape-loading dye-transfer experiments, cells were seeded on polyornithinecoated 35-mm-diameter dishes (Nunc, Roskilde, Denmark) at a density of $5 \times 10^{5}$ cells $/ \mathrm{mL}$. For hemichannel experiments cells were seeded $\left(2 \times 10^{5}\right.$ cells per well $)$ on glass coverslips (Gassalem, Limeil-Brévannes, France) placed inside 24-roundwell plate; area $1.9 \mathrm{~cm} 2 /$ well; (NunClon, Thermoscientific, Atlanta, GA, USA). Cellular medium, DMEM (Sigma-Aldrich, St-Louis MO, USA), supplemented with penicillin $(5 \mathrm{U} / \mathrm{ml})$, streptomycin (5 $\mu \mathrm{g} / \mathrm{ml}$; Invitrogen, Carlsbad, CA, USA), fungizone amphotericin B (500 ng/mL; Gibco, Life Technologies, Carlsbad, CA, USA), and 10\% FCS (Hyclone, Logan, UT, USA), was changed twice a week. When cells reached confluence, around 10 days in vitro (DIV), they were harvested with trypsin-EDTA (Invitrogen). The medium was changed twice a week until the experiments were carried out. In order to characterize the proportion of microglia in primary culture of astrocytes, the two cell types were identified by immunostaining with Isolectine $\mathrm{B} 4$ and GFAP antibodies, respectively.

\section{Products and Cell Treatments}

Astrocyte cultures were treated for $24 \mathrm{~h}$ with lipopolysaccharide (LPS, $1 \mu \mathrm{g} / \mathrm{ml}$ ) and/or the following antidepressants: fluoxetine, duloxetine, paroxetine, reboxetine, amitriptyline, imipramine, venlafaxine $(5,10$, or $20 \mu \mathrm{M}$, Sigma-Aldrich, Saint-Louis, MO, USA). Carbenoxolone (50 $\mu \mathrm{M}$, Sigma-Aldrich) was used as positive inhibitor control for gap junction channels. Drugs were prepared either in $\mathrm{H}_{2} \mathrm{O}$ or DMSO. Control cells received no treatment and were previously studied with vehicle (H20 or DMSO) which induced no changes in comparison with untreated cells.

\section{Determination of Gap Junctional Communication}

Experiments were performed by using the scrape-loading dyetransfer technique, as previously described (Meme et al., 2006). Briefly, cells were incubated at room temperature for $10 \mathrm{~min}$ in HEPES buffered salt solution containing (in $\mathrm{mM}$ ): $\mathrm{NaCl}, 140$; $\mathrm{KCl}, 5.4 ; \mathrm{CaCl}_{2}, 1.8 ; \mathrm{MgCl}_{2}, 1$; glucose, 10; HEPES, 5 at $\mathrm{pH}$ 7.4. Cells were then washed with a calcium-free HEPES solution for $1 \mathrm{~min}$ and the scrape loading and dye transfer assay (see Giaume et al., 2012) was carried out in the same calcium-free solution containing Lucifer yellow $\mathrm{CH}$ (427 Da, $1 \mathrm{mg} / \mathrm{ml}$ ). One minute after scraping procedure, cells were washed with the HEPES solution and then Lucifer yellow loaded in the cells was allowed to diffuse through gap junction channels for $8 \mathrm{~min}$. Photomicrographs were taken and data were quantified using NIS Nikon software. In all experiments, the fluorescence area of the first row of cells initially loaded, as measured in the presence of the gap junction channel inhibitor carbenoxolone $(50 \mu \mathrm{M}$, $24 \mathrm{~h}$ ), was subtracted from the total fluorescence area.

\section{Ethidium Bromide Uptake Experiments in Cortical Astrocyte Cultures}

Following $10 \mathrm{~min}$ exposure to $5 \mu \mathrm{M}$ ethydium bromide (EtBr), cells were washed with HEPES buffered salt solution containing (in $\mathrm{mM}$ ): $\mathrm{NaCl}, 140 ; \mathrm{KCl}, 5.4 ; \mathrm{CaCl}_{2}, 1.8 ; \mathrm{MgCl}_{2}, 1$; glucose, 10; HEPES, 5 at $\mathrm{pH}$ 7.4. After $10 \mathrm{~min}$ in fixing solution (4\% paraformaldehyde in $0.12 \mathrm{M}$ buffer phosphate) and rinsing with phosphate buffered saline (PBS), cells were mounted in Fluoromount-G mounting medium (Orellana et al., 2011). Images of astrocyte cultures were taken with a $40 \times$ objective using a confocal laser-scanning microscope (Leica TBCS SP5). Stacks of consecutive confocal images for $10 \mu \mathrm{m}$ at $0.49 \mu \mathrm{m}$ intervals were acquired with an argon ion laser at $488 \mathrm{~nm}$. Confocal images of EthBr uptake were analyzed with Image J software. The EtBr fluorescence intensity in the nuclei of astrocytes in each image was measured and the average of six images of different areas in the same culture was calculated the final measurement of dye uptake in that culture. 


\section{Western Blot}

After 24 h of treatment, cultures were rinsed with PBS 1X and added $75 \mu \mathrm{L}$ of a solution containing protease and phosphatase inhibitors (orthovanadate $1 \mathrm{mM}$; $\alpha$-glycerophosphate $10 \mathrm{mM}$ ), and complete miniprotease inhibitor (Roche Diagnostics, Meylan, France). Cells were then harvested by scraping with a rubber policeman and pelleted cells were added $20 \mu \mathrm{L}$ of 5X Laemmli sample buffer. Samples were boiled for $5 \mathrm{~min}$, placed on ice, and lysed by sonication (Ultrasonic cell disrupter, Microson, Bruxelles, Belgium). Then, samples were stored at $-20^{\circ} \mathrm{C}$. Proteins were measured with the Bio-Rad protein assay (Bio-Rad laboratories, Richmond, CA, USA). For each cell lysate sample, $20 \mu \mathrm{g}$ of proteins were separated on Bis-Tris $4-12 \%$ NuPAGE gels and electro-transferred to nitrocellulose sheets as previously described (Orellana et al., 2011). Non-specific protein binding was blocked by incubation of nitrocellulose sheets in tris-buffered saline (TBS) - Tween - milk solution (500 mL TBS 1X; $500 \mu \mathrm{L}$ Tween 20X; non-fat powder milk $25 \mathrm{~g}$ ) for $1 \mathrm{~h}$. Blots were then incubated overnight with primary antibody mouse Cx43 1:500 (Transduction Laboratories, Le Pont de Claix, France) at $4^{\circ} \mathrm{C}$, followed by $4 \times 15 \mathrm{~min}$ PBS washes. Blots were incubated with goat anti-mouse antibody 1:2500 conjugated to horseradish peroxidase (Tébu, Le PerrayEn-Yveline, France). Immunoreactivity was detected by ECL detection using the SuperSignal kit (Pierce, Rockford, IL, USA) according to instructions. Blots were then reprobed with mouse monoclonal anti-glyceraldehyde 3-phosphate dehydrogenase peroxidase (Sigma-Aldrich, 1:10,000) to check the protein load. Chemiluminescence imaging was performed on a LAS4000 (Fujifilm, Stamford, CT, USA). Semiquantitative densitometric analysis was performed with ImageJ software after scanning the bands.

\section{Statistical Analysis}

For each data group, results are expressed as mean \pm SEM and $n$ refers to the number of independent experiments. KruskalWallis test and one-way ANOVA, followed, respectively, by Dunn and Bonferroni post tests, were used as well as unpaired $t$-test. Differences are considered significant at ${ }^{*} P<0.05,{ }^{* *} P<0.01$, ${ }^{* * *} P<0.001$ versus control, $+P<0.05,++P<0.01$, and $+++P<0.001$ vs. LPS. GraphPad Prism 5 software (GraphPad Software, La Jolla, CA, USA) was used for calculations.

\section{RESULTS}

The doses of the antidepressants were chosen in accordance with literature addressing the neuropharmacokinetics of the tested molecules of interest. Accordingly, cultured cortical astrocytes were treated with concentrations identical to those reported for brains of human or rodent after treatment with clinically relevant doses from in vivo studies: for fluoxetine, $20 \mu \mathrm{M}$ in human brain is achieved at $20 \mathrm{mg} /$ day (see Henry et al., 2005); for venlafaxine, $10 \mu \mathrm{M}$ in mice brain is reached at $20 \mathrm{mg} / \mathrm{kg}$ (Karlsson et al., 2011); for duloxetine, $4.2 \mathrm{mg} / \mathrm{kg}$ in rat leads to $10 \mu \mathrm{M}$ in brain (Kielbasa and Stratford, 2012). For the other molecules (amitriptyline, imipramine, paroxetine, reboxetine) the doses were selected below cell toxicity that was identified by microscopic examination of astrocyte cultures treated for $24 \mathrm{~h}$, related to changed cell morphology and entry of Lucifer yellow into damaged cells. More precisely the lack of toxicity of the selected doses was routinely validated by the absence of Lucifer yellow unspecific uptake in area far from the scrape lines in scrape-loading dye-transfer experiments (see Figure 1A). Based on these criterions all molecules were tested at concentrations between 5 and $20 \mu \mathrm{M}(24 \mathrm{~h})$ for toxicity; we observed that fluoxetine at $20 \mu \mathrm{M}$, paroxetine $10 \mu \mathrm{M}$, and duloxetine $20 \mu \mathrm{M}$ were toxic at these indicated doses, consequently these molecules were tested at lower doses.

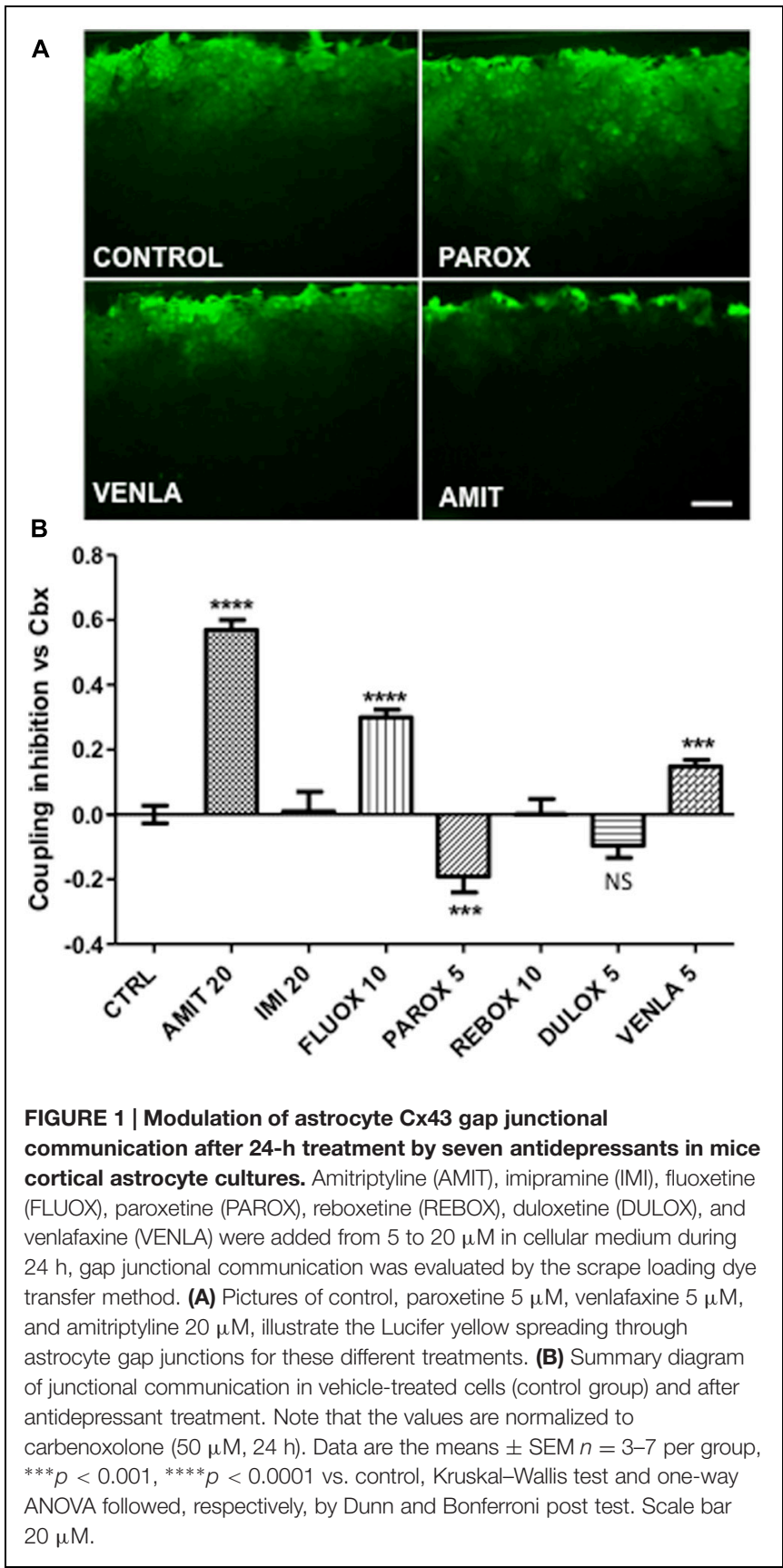


The first question addressed during this screening with antidepressants was their effect on the level of Cx43 expression investigated by western blotting. As indicated in Table 2, the seven tested antidepressants did not significantly modify the level of expression of $\mathrm{Cx} 43$ studied in cultured cortical mouse astrocytes ( $n=3-6$ per group, $p>0.05$ One way ANOVA, Dunn post test).

The effect of the selected antidepressants on gap junctional communication was then tested by using the scrape-loading dye transfer technique (see Giaume et al., 2012). In control condition after $10 \mathrm{~min}$ the Lucifer yellow diffuses widely perpendicular to the scrape line that indicates a high level of gap junctional communication (Figure 1A, control). As illustrated in Figure 1B, three different effects were observed. Three antidepressants, amitriptyline $(20 \mu \mathrm{M}$; Figure 1A), fluoxetine $(10 \mu \mathrm{M})$, and venlafaxine ( $5 \mu \mathrm{M}$; Figure 1A) reduced intercellular dye spread by $57 \%(n=6), 25 \%(n=6)$, and $15 \%(n=6)$, respectively. In contrast, paroxetine ( $5 \mu \mathrm{M}$; Figure 1A) increased dye coupling by $19 \%(n=7)$. Finally, imipramine $(20 \mu \mathrm{M}, n=3)$, reboxetine $(10 \mu \mathrm{M}, n=6)$ and duloxetine $(5 \mu \mathrm{M}, n=9)$ had no statistically significant action on the level of intercellular communication between astrocytes, neither at these doses nor at higher non-toxic doses.

In normal condition, astrocytes in culture as well as in acute slices are characterized by a high level of gap junctional communication and low hemichannel activity (Bennett et al., 2003; Retamal et al., 2007; but see Chever et al., 2014). However, in most pathological situations involving brain inflammation, a reactive gliosis is associated with elevated hemichannel activity in astrocytes (see Bennett et al., 2012; Giaume et al., 2013). Such low hemichannel activity was also observed in our culture condition (Figure 2A). Therefore, to induce hemichannel activity we treated our cortical primary cultures, in which $11 \%(n=9)$ of isolectin B4-positive microglia versus GFAP-positive astrocytes were present, with the endotoxin LPS. As already reported for in vitro astrocytes (Retamal et al., 2007), we observed that LPS treatment $(1 \mu \mathrm{g} / \mathrm{ml}, 24 \mathrm{~h})$ inhibited gap junctional communication by $64 \%(n=6)$, in such condition we found that the antidepressants amitriptyline $(20 \mu \mathrm{M}, n=4)$, imipramine (20 $\mu \mathrm{M}, n=4)$, venlafaxine ( $\mu \mathrm{M}, n=3)$, and duloxetine ( $5 \mu \mathrm{M}, n=4)$ did not reverse the inhibition induced by LPS, when co-treated during $24 \mathrm{~h}$ in astrocyte cultures. However, paroxetine (5 $\mu \mathrm{M}, n=4)$ and reboxetine $(10 \mu \mathrm{M}, n=3)$ reversed LPS-induced uncoupling, in a low but significant manner, respectively, by $17 \%(n=4)$ and $10 \%(n=3)$ whereas fluoxetine $(10 \mu \mathrm{M})$ improved it by $10 \%(n=4$; data not illustrated). Moreover, we found that LPS treatment $(1 \mu \mathrm{g} / \mathrm{ml}$, $24 \mathrm{~h}$ ) increased by $104 \%(n=7)$ the uptake of ethidium bromide $(\mathrm{EtBr})$ in GFAP-positive astrocytes indicating that, as previously reported (Retamal et al., 2007; Abudara et al., 2015) hemichannels in cortical astrocytes were activated (Figure 2A). As expected EtBr uptake was inhibited by $93 \%(n=3)$ in the presence of carbenoxolone $(50 \mu \mathrm{M} ; 24 \mathrm{~h})$ indicating that this uptake is mediated through hemichannel activity (Figure 2B). All the seven antidepressants tested had a significant inhibitor effect on the LPS-induced EtBr uptake, however, with difference in their efficiency. Indeed, fluoxetine $(10 \mu \mathrm{M})$, paroxetine $(5 \mu \mathrm{M})$, and duloxetine ( $5 \mu \mathrm{M}$; Figure 2A) had pronounced effect and inhibited EtBr uptake by $97 \%(n=3), 93 \%(n=3)$, and $111 \%(n=4)$, respectively (Figure 2B). Meanwhile, amitriptyline $(20 \mu \mathrm{M}$; Figure $2 \mathrm{~A})$, imipramine $(20 \mu \mathrm{M})$, reboxetine $(10 \mu \mathrm{M})$, and venlafaxine $(5 \mu \mathrm{M})$ had milder effect with $45 \%(n=6)$, $28 \%(n=3), 52 \%(n=3)$, and $23 \%(n=4)$, respectively (Figure 2B).

\section{DISCUSSION}

The objective of the present study was to investigate the effects of a panel of antidepressants on the property of the astroglial Cx43, a membrane protein widely expressed in glial cells that contributes actively to neuroglial interaction in normal and disease brain (see Ransom and Giaume, 2013). For this purpose we undertook an in vitro screening of seven antidepressants from four different classes (TCA, SSRI, NRI, SNRI), all implied in serotonin and/or noradrenaline reuptake inhibition, to characterize their action on astroglial $\mathrm{Cx} 43$ at diverse levels: protein expression, gap junctional communication and hemichannel function. We selected a simple cellular system, primary cultures of mouse cortical and striatal astrocytes in which only $\mathrm{Cx} 43$ is detected (Dermietzel et al., 1991; Giaume et al., 1991; Koulakoff et al., 2008). The tested concentrations were determined either based on the literature, when clinically relevant doses were available, or by establishing experimentally their threshold of toxicity for $24 \mathrm{~h}$ treatment (see Results section). While we did not observe any significant change in $\mathrm{Cx} 43$ protein level, we found that antidepressants had differential effects on astroglial Cx43-based gap junctional communication as summarized in Table 2. These

TABLE 2 | Summary table of the effect of seven antidepressants for four different classes: tricyclic (TCA), selective serotonin reuptake inhibitor (SSRI), noradrenaline reuptake inhibitor (NRI), serotonin noradrenaline reuptake inhibitor (SNRI), on Cx43 expression and channel functions in cultured astrocytes.

\begin{tabular}{llcccc}
\hline Antidepressant & Class & Concentration tested $(\boldsymbol{\mu}$ M) & Cx43 expression & Effect on gap junctional coupling & Effect on hemichannels \\
\hline Amitriptyline & TCA & 20 & No significant effect & Inhibition & Mild inhibition \\
Imipramine & TCA & 20 & No significant effect & No effect & Mild inhibition \\
Fluoxetine & SSRI & 10 & No significant effect & Inhibition & Total inhibition \\
Paroxetine & SSRI & 5 & No significant effect & Increase & Total inhibition \\
Reboxetine & NRI & 10 & No significant effect & No effect & Mild inhibition \\
Duloxetine & SNRI & 5 & No significant effect & No effect & Total inhibition \\
Venlafaxine & SNRI & 5 & No significant effect & Inhibition & Mild inhibition
\end{tabular}




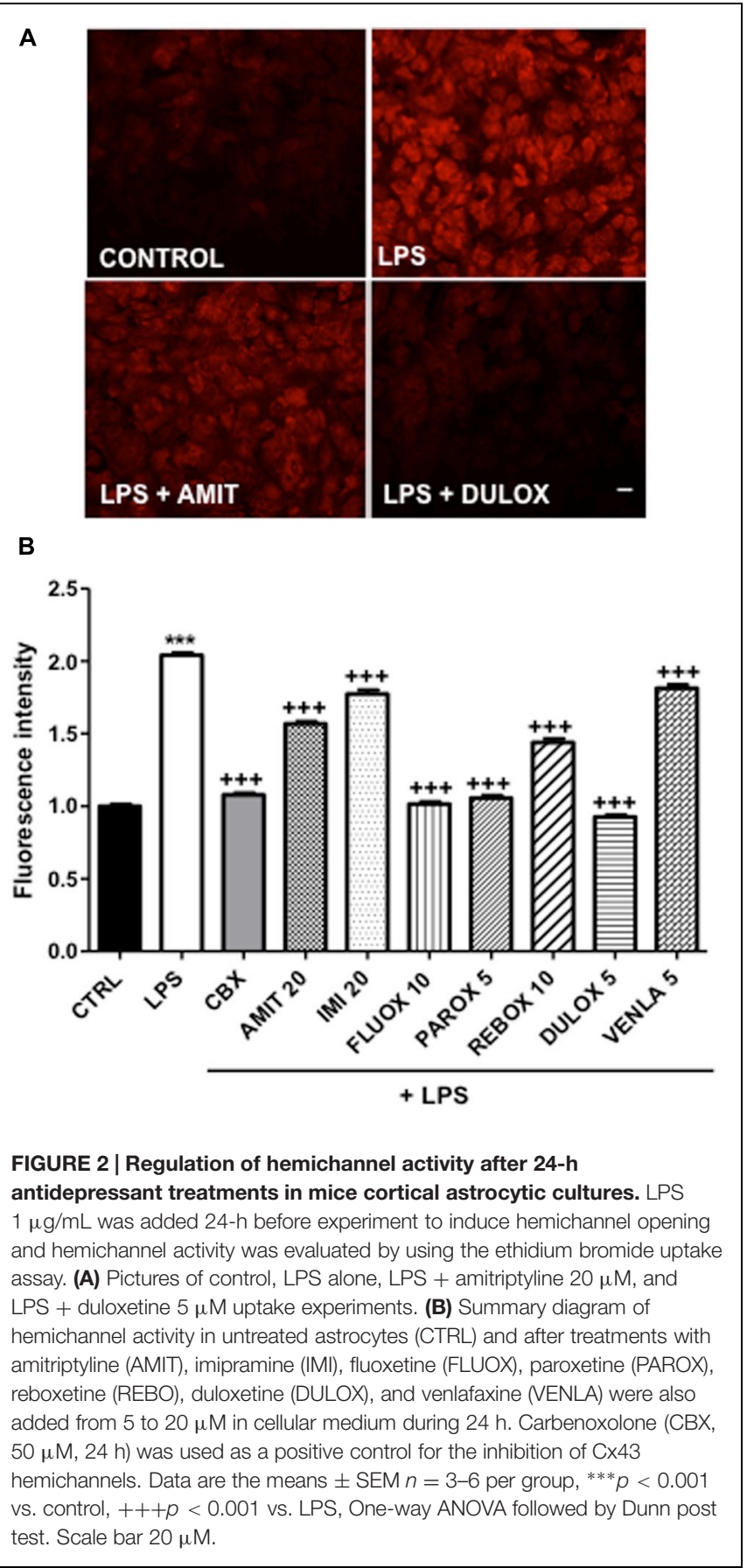

results are different compared those reported in the few articles that so far have addressed these properties for some of the antidepressants used in the present study, i.e., amitriptyline, fluoxetine, and duloxetine (see Tables 1 and 2). Indeed, Sun et al. (2012) and Morioka et al. (2014) reported, respectively, an enhancement in Cx43 mRNA and protein levels in astrocytes from cultured rat astrocytes treated with amitriptyline and in the prefrontal cortex of rats chronically treated with duloxetine (Sun et al., 2012; Morioka et al., 2014). Additionally, two studies have also shown a rise in $\mathrm{Cx} 43$ protein levels in the prefrontal cortex after in vivo treatment with fluoxetine (Fatemi et al., 2008; Sun et al., 2012), as well as in human astrocytoma cultures (Mostafavi et al., 2008). However, no changes in $\mathrm{Cx} 43$ gap junctional communication have been found after in vivo treatments with both fluoxetine and duloxetine in rats (Sun et al., 2012) whereas this Cx43 function was increased after amitriptyline treatment in cultured rat astrocytes (Morioka et al., 2014). In our experiments (see Table 2 ) only paroxetine ( $5 \mathrm{mM}$ ) was found to increase gap junctional communication while duloxetine $(5 \mu \mathrm{M})$ has a slight, but not statistically significant increasing effect. Imipramine $(20 \mu \mathrm{M})$ and reboxetine $(10 \mu \mathrm{M})$ had no effect and an inhibition was observed with amitriptyline $(20 \mu \mathrm{M})$, fluoxetine $(10 \mu \mathrm{M})$, and venlafaxine $(5 \mu \mathrm{M})$. These effects were not specific to a defined class of antidepressants and allow for taking a step back regarding results from other models. Indeed, our study demonstrates that the link between antidepressants and $\mathrm{Cx} 43$-mediated intercellular communication in astrocyte is likely more complex than the literature consensual interpretation concerning an increase of Cx43 expression and function, and that opposed effects are observed within a same therapeutic class. However, when pointing out the differences between our results and the current literature, several parameters must be taken into account. First, the models of study differed: we used cultured mouse astrocytes, while Sun et al. (2012) and Fatemi et al. (2008) worked in vivo on rats, and others used cell culture models from various species and cellular types in culture (human astrocytoma and rat astrocytes). Second, dosage, time, and chronicity of the treatments also differ. Indeed, our in vitro tested concentrations were non-toxic and similar to what is found in the brain in pharmacokinetics studies addressing clinically relevant doses for these molecules, and ranged from 1 to $100 \mu \mathrm{M}$ in the literature. In literature, in vitro treatments were administered for several minutes to $48 \mathrm{~h}$ (see Table 1). We treated for $24 \mathrm{~h}$, as for example preliminary trials of 48 -h treatments with amitriptyline $(20 \mu \mathrm{M})$ induced cell toxicity. In addition, in the studies that were performed using in vivo models, animals received chronic treatment (see Table 1) that certainly involved more integrated and complex mechanisms. Taken as a whole these information complete and extend the knowledge about the effect of antidepressants on gap junctional communication in astrocytes. Finally, as no changes in Cx43 expression were detected after treatment with antidepressant, we suggested that they act at the post-translational level.

Up-to-now there was no indication about the effect of antidepressants on the other channel function of $\mathrm{Cx} 43$ in astrocytes, i.e., the hemichannel activity. This lack of information can be attributed to the fact that for astrocytes this activity has been established much latter than the gap junction channel function and that hemichannels are weakly opened in normal conditions hence requiring a pathological context to be activated (see Bennett et al., 2003; Giaume et al., 2013). We confirmed this feature on untreated primary cortical cultures as the $\mathrm{Cx}$ channel inhibitor carbenoxolone had no significant no effect (data not shown) on the uptake of EtBr (see Giaume et al., 2012). However, we took advantage that our LPS-stimulated cultures contained a non-negligible proportion of microglial cells (11\%), a situation already identified to activated $\mathrm{Cx} 43$ hemichannels and 
to reduce gap junctional communication in astrocytes (Retamal et al., 2007). Indeed, we previously showed that when LPSstimulated microglia are co-cultured with astrocytes two proinflammatory cytokines are released, i.e., TNF- $\alpha$ and IL- $1 \beta$, activating $\mathrm{Cx} 43$ hemichannel activity in astrocytes (Retamal et al., 2007; Abudara et al., 2015). Interestingly, LPS has been reported to cause time-dependent behavioral alterations with sickness behavior (Huang et al., 2008) and a depressive-like behavior observed $24 \mathrm{~h}$ after LPS challenge (Painsipp et al., 2011; Custódio et al., 2013); and it is noteworthy that this effect is reversed by fluoxetine (Yirmiya et al., 2001), imipramine (Tomaz et al., 2014), paroxetine and duloxetine (Ohgi et al., 2013). Besides, the level of TNF- $\alpha$ and IL- $1 \beta$, are increased after LPS treatments in animal model, similarly to the increase observed in subjects with major depression disease (Seidel et al., 1995; Sluzewska et al., 1996; Dowlati et al., 2010; Hannestad et al., 2011). On this basis LPS has been proposed as an inducer of depressive-like context (Mello et al., 2013; Ohgi et al., 2013) confirming the interest of LPS in the evaluation of antidepressant mechanisms. Using the EtBr uptake assay we found that all tested antidepressants had an inhibitory effect on LPS-induced astroglial hemichannel activity. The effect on Cx43-based hemichannel function was correlated when considering the class of the antidepressants, the SSRIs (fluoxetine, paroxetine) induced a strong inhibition while the TCAs (amitriptyline, imipramine) and NRI (reboxetine) had mild effect, the treatment with SNRI (duloxetine, venlafaxine) resulting in mixed inhibition efficiency. Interestingly, several of these antidepressants are known to have an inhibitory effect on the production of pro-inflammatory cytokines, in particular TNF- $\alpha$ and IL-1 $\beta$, fluoxetine (Chiou et al., 2006; Tai et al., 2009; Valera et al., 2014), amitriptyline (Obuchowicz et al., 2006; Tai et al., 2009), paroxetine (Liu et al., 2014), and imipramine (Lee et al., 2012). Meanwhile venlafaxine, which presents the lowest inhibitory effect on LPS-induced hemichannel activity (23\%), is the only tested compound that increased the level of TNF- $\alpha$ (Valera et al., 2014). Taken as a whole these results could support the idea that antidepressants may control $\mathrm{Cx} 43$ hemichannel activity through the production of TNF-a and/or IL-1 $\beta$ as the result of a reduction of microglial activation. However, just paroxetine and reboxetine modestly reversed the inhibition of gap junctional communication induced by LPS, it could consequently imply that antidepressant effects are not targeting microglia-released interleukins. It could also suggest that the antidepressant inhibitory effects on hemichannels are acting downstream to the microglial step and/or more directly on the Cx43 hemichannel function. Nevertheless, more work is needed to decipher the specific mechanisms involved in the

\section{REFERENCES}

Abudara, V., Roux, L., Dallérac, G., Matias, I., Dulong, J., Mothet, J. P., et al. (2015). Activated microglia impairs neuroglial interaction by opening Cx43 hemichannels in hippocampal astrocytes. Glia 63, 795-811. doi: 10.1002/glia.22785

Araque, A., Parpura, V., Sanzgiri, R. P., and Haydon, P. G. (1999). Tripartite synapses: glia, the unacknowledged partner. Trends Neurosci. 22, 208-215. doi: 10.1016/S0166-2236(98)01349-6 regulation of astroglial Cx channels by antidepressants, an aim that is beyond the scope of the present study.

Interestingly, hemichannel activity in astrocytes has been shown to provide a pathway for glutamate release (Ye et al., 2003; Abudara et al., 2015). Consequently, the antidepressant inhibitory action on hemichannel activity could support the current hypothesis of the action of these drugs on glutamine/glutamate metabolic cycle (Garakani et al., 2013) and glutamate transmission (Gorman and Docherty, 2010; Sanacora and Banasr, 2013) in the pathophysiology of major depression (Etiévant et al., 2013). Finally, glutamate gliotransmission mediated by $\mathrm{Cx} 43$ hemichannels has been recently reported to occur in a model of chronic restraint stress (Orellana et al., 2015) which is admitted as a model inducing depressive-like symptoms in rodents (Levinstein and Samuels, 2014).

The present study reflects the need to re-evaluate the statement according to which an alternative strategy for antidepressive treatments is to target astroglial $\mathrm{Cx} 43$ and to increase gap junctional communication. This proposition was solely based on reports indicating that several antidepressants favor Cx43 expression levels while a few have investigated their effect on the functional aspect, i.e., gap junctional communication. Based on the present results the effect of antidepressant drugs on astroglial gap junctions appears more complex than initially thought and suggests that $\mathrm{Cx} 43$ hemichannel activity in astrocytes may be part of the mode of action of these drugs. Finally, our observation, and in particular those related to hemichannel activity, could benefit to the understanding of the mode of action of antidepressants in other pathologies treated by antidepressants such as neuropathic pain (Dworkin et al., 2010; Finnerup et al., 2015) and for which the involvement of glial $\mathrm{Cx} 43$ hemichannel activity has been proposed (Chen et al., 2014).

\section{AUTHOR CONTRIBUTIONS}

TJ and CG contributed to the study design, TJ and AP conducted the experiments, CG wrote the initial draft; TJ, CG, FM, MC contributed to the writing of the manuscript.

\section{ACKNOWLEDGMENTS}

This study was supported by the Collège de France and the INSERM. The authors wish to thank Dr. A. Koulakoff for constant and helpful discussions along this work.

Bennett, M. V., Contreras, J. E., Bukauskas, F. F., and Sáez, J. C. (2003). New roles for astrocytes: gap junction hemichannels have something to communicate. Trends Neurosci. 26, 610-617. doi: 10.1016/j.tins.2003.09.008

Bennett, M. V., Garré, J. M., Orellana, J. A., Bukauskas, F. F., Nedergaard, M., Giaume, C., et al. (2012). Connexin and pannexin hemichannels in inflammatory responses of glia and neurons. Brain Res. 1487, 3-15. doi: 10.1016/j.brainres.2012.08.042

Bernard, R., Kerman, I. A., Thompson, R. C., Jones, E. G., Bunney, W. E., Barchas, J. D., et al. (2011). Altered expression of glutamate signaling, growth factor, 
and glia genes in the locus coeruleus of patients with major depression. Mol. Psychiatry 16, 634-646. doi: 10.1038/mp.2010.44

Chen, G., Park, C. K., Xie, R. G., Berta, T., Nedergaard, M., and Ji, R. R. (2014). Connexin- 43 induces chemokine release from spinal cord astrocytes to maintain late-phase neuropathic pain in mice. Brain 137(Pt 8), 2193-2209. doi: 10.1093/brain/awu140

Chever, O., Lee, C. Y., and Rouach, N. (2014). Astroglial connexin43 hemichannels tune basal excitatory synaptic transmission. J. Neurosci. 34, 11228-11232. doi: 10.1523/JNEUROSCI.0015-14.2014

Chiou, S. H., Chen, S. J., Peng, C. H., Chang, Y. L., Ku, H. H., Hsu, W. M., et al. (2006). Fluoxetine up-regulates expression of cellular FLICE-inhibitory protein and inhibits LPS-induced apoptosis in hippocampus-derived neural stem cell. Biochem. Biophys. Res. Commun. 343, 391-400. doi: 10.1016/j.bbrc.2006.02.180

Colangelo, A. M., Alberghina, L., and Papa, M. (2014). Astrogliosis as a therapeutic target for neurodegenerative diseases. Neurosci. Lett. 565, 59-64. doi: 10.1016/j.neulet.2014.01.014

Cotrina, M. L., and Nedergaard, M. (2012). Brain connexins in demyelinating diseases: therapeutic potential of glial targets. Brain Res. 1487, 61-68. doi: 10.1016/j.brainres.2012.07.003

Custódio, C. S., Mello, B. S., Cordeiro, R. C., de Araújo, F. Y., Chaves, J. H., Vasconcelos, S. M., et al. (2013). Time course of the effects of lipopolysaccharide on prepulse inhibition and brain nitrite content in mice. Eur. J. Pharmacol. 713 , 31-38. doi: 10.1016/j.ejphar.2013.04.040

Dermietzel, R., Hertberg, E. L., Kessler, J. A., and Spray, D. C. (1991). Gap junctions between cultured astrocytes: immunocytochemical, molecular, and electrophysiological analysis. J. Neurosci. 11, 1421-1432.

Dowlati, Y., Herrmann, N., Swardfager, W., Liu, H., Sham, L., Reim, E. K., et al. (2010). A meta-analysis of cytokines in major depression. Biol. Psychiatry 67, 446-457. doi: 10.1016/j.biopsych.2009.09.033

Dworkin, R. H., O'Connor, A. B., Audette, J., Baron, R., Gourlay, G. K., Haanpää, M. L., et al. (2010). Recommendations for the pharmacological management of neuropathic pain: an overview and literature update. Mayo Clin. Proc. 85, S3-S14. doi: $10.4065 / \mathrm{mcp} .2009 .0649$

Ernst, C., Nagy, C., Kim, S., Yang, J. P., Deng, X., Hellstrom, I. C., et al. (2011). Dysfunction of astrocyte connexins 30 and 43 in dorsal lateral prefrontal cortex of suicide completers. Biol. Psychiatry 70, 312-319. doi: 10.1016/j.biopsych.2011.03.038

Etiévant, A., Lambás-Señas, L., Scarna, H., Lucas, G., and Haddjeri, N. (2013). Astrocytes and gliotransmitters: new players in the treatment of major depression? Curr. Drug Targets 14, 1295-1307.

Fatemi, S. H., Folsom, T. D., Reutiman, T. J., and Lee, S. (2008). Expression of astrocytic markers aquaporin 4 and connexin 43 is altered in brains of subjects with autism. Synapse 62, 501-507. doi: 10.1002/syn.20519

Finnerup, N. B., Attal, N., Haroutounian, S., McNicol, E., Baron, R., Dworkin, R. H., et al. (2015). Pharmacotherapy for neuropathic pain in adults: a systematic review and meta-analysis. Lancet Neurol. 14, 162-173. doi: 10.1016/S1474-4422(14)70251-0

Freitas-Andrade, M., and Naus, C. C. (2015). Astrocytes in neuroprotection and neurodegeneration: the role of connexin 43 and pannexin1. Neuroscience doi: 10.1016/j.neuroscience.2015.04.035 [Epub ahead of print].

Froger, N., Orellan, J. A., Calvo, C. F., Amigou, E., Kozoriz, M. G., Naus, C. C., et al. (2010). Inhibition of cytokine-induced connexin 43 hemichannel activity in astrocytes is neuroprotective. Mol. Cell. Neurosci. 45, 37-46. doi: 10.1016/j.mcn.2010.05.007

Garakani, A., Martinez, J. M., Yehuda, R., and Gorman, J. M. (2013). Cerebrospinal fluid levels of glutamate and corticotropin releasing hormone in major depression before and after treatment. J. Affect. Disord. 146, 262-265. doi: 10.1016/j.jad.2012.06.037

Giaume, C., Fromaget, C., el Aoumari, A., Cordier, J., Glowinski, J., and Gros, D. (1991). Gap junctions in cultured astrocytes: single-channel currents and characterization of channel-forming protein. Neuron 6, 133-143. doi: 10.1016/0896-6273(91)90128-M

Giaume, C., Kirchhoff, F., Matute, C., Reichenbach, A., and Verkhratsky, A. (2007). Glia: the fulcrum of brain diseases. Cell Death Differ. 14, 1324-1335. doi: $10.1038 /$ sj.cdd.4402144

Giaume, C., Leybaert, L., Naus, C. C., and Sáez, J. C. (2013). Connexin and pannexin hemichannels in brain glial cells: properties, pharmacology, and roles. Front. Pharmacol. 4:88. doi: 10.3389/fphar.2013.00088
Giaume, C., Orellana, J. A., Abudara, V., and Sáez, J. C. (2012). Connexin-based channels in astrocytes: how to study their properties. Methods Mol. Biol. 814, 283-303. doi: 10.1007/978-1-61779-452-0_19

Gorman, J. M., and Docherty, J. P. (2010). A hypothesized role for dendritic remodeling in the etiology of mood and anxiety disorders. J. Neuropsychiatry Clin. Neurosci. 22, 256-264. doi: 10.1176/appi.neuropsych.22.3.256

Halassa, M. M., and Haydon, P. G. (2010). Integrated brain circuits: astrocytic networks modulate neuronal activity and behavior. Annu. Rev. Physiol. 72, 335-355. doi: 10.1146/annurev-physiol-021909-135843

Hannestad, J., DellaGioia, N., and Bloch, M. (2011). The effect of antidepressant medication treatment on serum levels of inflammatory cytokines: a metaanalysis. Neuropsychopharmacology 36, 2452-2459. doi: 10.1038/npp.2011.132

Harris, A. L. (2007). Connexin channel permeability to cytoplasmic molecules. Prog. Biophys. Mol. Biol. 94, 120-143. doi: 10.1016/j.pbiomolbio.2007.03.011

Henry, M. E., Schmidt, M. E., Hennen, J., Villafuerte, R. A., Butman, M. L., Tran, P., et al. (2005). A comparison of brain and serum pharmacokinetics of R-fluoxetine and racemic fluoxetine: a 19-F MRS study. Neuropsychopharmacology 30, 1576-1583. doi: 10.1038/sj.npp.1300749

Huang, Y., Henry, C. J., Dantzer, R., Johnson, R. W., and Godbout, J. P. (2008). Exaggerated sickness behavior and brain proinflammatory cytokine expression in aged mice in response to intracerebroventricular lipopolysaccharide. Neurobiol. Aging 29, 1744-1753. doi: 10.1016/j.neurobiolaging.2007.04.012

Kang, J., Kang, N., Lovatt, D., Torres, A., Zhao, Z., Lin, J., et al. (2008). Connexin 43 hemichannels are permeable to ATP. J. Neurosci. 28, 4702-4711. doi: 10.1523/JNEUROSCI.5048-07.2008

Karlsson, L., Hiemke, C., Carlsson, B., Josefsson, M., Ahlner, J., Bengtsson, F., et al. (2011). Effects on enantiomeric drug disposition and open-field behavior after chronic treatment with venlafaxine in the P-glycoprotein knockout mice model. Psychopharmacology (Berl.) 215, 367-377. doi: 10.1007/s00213-010-2148-5

Kawasaki, A., Hayashi, T., Nakachi, K., Trosko, J. E., Sugihara, K., Kotake, Y., et al. (2009). Modulation of connexin 43 in rotenone-induced model of Parkinson's disease. Neuroscience 160, 61-68. doi: 10.1016/j.neuroscience.2009. 01.080

Kielbasa, W., and Stratford, R. E. Jr. (2012). Exploratory translational modeling approach in drug development to predict human brain pharmacokinetics and pharmacologically relevant clinical doses. Drug Metab. Dispos. 40, 877-883. doi: 10.1124/dmd.111.043554

Koulakoff, A., Ezan, P., and Giaume, C. (2008). Neurons control the expression of connexin 30 and connexin 43 in mouse cortical astrocytes. Glia 56, 1299-1311. doi: 10.1002/glia.20698

Koulakoff, A., Mei, X., Orellana, J. A., Sáez, J. C., and Giaume, C. (2012). Glial connexin expression and function in the context of Alzheimer's disease. Biochim. Biophys. Acta 1818, 2048-2057. doi: 10.1016/j.bbamem.2011.10.001

Lee, Y. H., Kim, S. H., Kim, Y., Lim, Y., Ha, K., and Shin, S. Y. (2012). Inhibitory effect of the antidepressant imipramine on NF-кB-dependent CXCL1 expression in TNF $\alpha$-exposed astrocytes. Int. Immunopharmacol. 12, 547-555. doi: 10.1016/j.intimp.2012.01.011

Levinstein, M. R., and Samuels, B. A. (2014). Mechanisms underlying the antidepressant response and treatment resistance. Front. Behav. Neurosci. 8:208. doi: $10.3389 /$ fnbeh.2014.00208

Liu, R. P., Zou, M., Wang, J. Y., Zhu, J. J., Lai, J. M., Zhou, L. L., et al. (2014). Paroxetine ameliorates lipopolysaccharide-induced microglia activation via differential regulation of MAPK signaling. J. Neuroinflammation 11, 47. doi: 10.1186/1742-2094-11-47

Lundgaard, I., Osório, M. J., Kress, B. T., Sanggaard, S., and Nedergaard, M. (2014). White matter astrocytes in health and disease. Neuroscience 276, 161-173. doi: 10.1016/j.neuroscience.2013.10.050

Mello, B. S., Monte, A. S., McIntyre, R. S., Soczynska, J. K., Custódio, C. S., Cordeiro, R. C., et al. (2013). Effects of doxycycline on depressive-like behavior in mice after lipopolysaccharide (LPS) administration. J. Psychiatr. Res. 47, 1521-1529. doi: 10.1016/j.jpsychires.2013.06.008

Meme, W., Calvo, C. F., Froger, N., Ezan, P., Amigou, E., Koulakoff, A., et al. (2006). Proinflammatory cytokines released from microglia inhibit gap junctions in astrocytes: potentiation by b -amyloid. FASEB J. 20, 494-496.

Miguel-Hidalgo, J. J., Wilson, B. A., Hussain, S., Meshram, A., Rajkowska, G., and Stockmeier, C. A. (2014). Reduced connexin 43 immunolabeling in the orbitofrontal cortex in alcohol dependence and depression. J. Psychiatr. Res. 55, 101-109. doi: 10.1016/j.jpsychires.2014.04.007 
Morioka, N., Suekama, K., Zhang, F. F., Kajitani, N., Hisaoka-Nakashima, K., Takebayashi, M., et al. (2014). Amitriptyline up-regulates connexin43-gap junction in rat cultured cortical astrocytes via activation of the p38 and c-Fos/AP-1 signalling pathway. Br. J. Pharmacol. 171, 2854-2867. doi: 10.1111/bph.12614

Mostafavi, H., Khaksarian, M., Joghataei, M. T., Hassanzadeh, G., Soleimani, M., Eftekhari, S., et al. (2008). Fluoxetin upregulates connexin 43 expression in astrocyte. Basic Clin. Neurosci. 5, 74-79.

Mylvaganam, S., Ramani, M., Krawczyk, M., and Carlen, P. L. (2014). Roles of gap junctions, connexins, and pannexins in epilepsy. Front. Physiol. 5:172. doi: 10.3389/fphys.2014.00172

Nagy, J. I., Dudek, F. E., and Rash, J. E. (2004). Update on connexins and gap junctions in neurons and glia in the mammalian nervous system. Brain Res. Brain Res. Rev. 47, 191-215. doi: 10.1016/j.brainresrev.2004.05.005

Naus, C. C., and Laird, D. W. (2010). Implications and challenges of connexin connections to cancer. Nat. Rev. Cancer 10, 435-441. doi: 10.1038/nrc2841

Obuchowicz, E., Kowalski, J., Labuzek, K., Krysiak, R., Pendzich, J., and Herman, Z. S. (2006). Amitriptyline and nortriptyline inhibit interleukin-1 release by rat mixed glial and microglial cell cultures. Int. J. Neuropsychopharmacol. 9, 27-35. doi: $10.1017 / S 146114570500547 X$

Ohgi, Y., Futamura, T., Kikuchi, T., and Hashimoto, K. (2013). Effects of antidepressants on alternations in serum cytokines and depressive-like behavior in mice after lipopolysaccharide administration. Pharmacol. Biochem. Behav. 103, 853-859. doi: 10.1016/j.pbb.2012.12.003

Orellana, J. A., Avendaño, B. C., and Montero, T. D. (2014). Role of connexins and pannexins in ischemic stroke. Curr. Med. Chem. 21, 2165-2182. doi: 10.2174/0929867321666131228191714

Orellana, J. A., Moraga-Amaro, R., Díaz-Galarce, R., Rojas, S., Maturana, C. J., Stehberg, J., et al. (2015). Restraint stress increases hemichannel activity in hippocampal glial cells and neurons. Front. Cell. Neurosci. 9:102. doi: $10.3389 /$ fncel.2015.00102

Orellana, J. A., Shoji, K. F., Abudara, V., Ezan, P., Amigou, E., Sáez, P. J., et al. (2011). Amyloid $\beta$-induced death in neurons involves glial and neuronal hemichannels. J. Neurosci. 31, 4962-4977. doi: 10.1523/JNEUROSCI.641710.2011

Painsipp, E., Köfer, M. J., Sinner, F., and Holzer, P. (2011). Prolonged depressionlike behavior caused by immune challenge: influence of mouse strain and social environment. PLoS ONE 6:e20719. doi: 10.1371/journal.pone.0020719

Pannasch, U., Vargová, L., Reingruber, J., Ezan, P., Holcman, D., Giaume, C., et al. (2011). Astroglial networks scale synaptic activity and plasticity. Proc. Natl. Acad. Sci. U.S.A. 108, 8467-8472. doi: 10.1073/pnas.1016650108

Parpura, V., Heneka, M. T., Montana, V., Oliet, S. H., Schousboe, A., Haydon, P. G., et al. (2012). Glial cells in (patho)physiology. J. Neurochem. 121, 4-27. doi: 10.1111/j.1471-4159.2012.07664.x

Pérez-Alvarez, A., and Araque, A. (2013). Astrocyte-neuron interaction at tripartite synapses. Curr. Drug Targets 14, 1220-1224. doi: $10.2174 / 13894501113149990203$

Rajkowska, G., and Stockmeier, C. A. (2013). Astrocyte pathology in major depressive disorder: insights from human postmortem brain tissue. Curr. Drug Targets 14, 1225-1236. doi: 10.2174/13894501113149990156

Rana, S., and Dringen, R. (2007). Gap junction hemichannel-mediated release of glutathione from cultured rat astrocytes. Neurosci. Lett. 415, 45-48. doi: 10.1016/j.neulet.2006.12.043

Ransom, B. R., and Giaume, C. (2013). "Gap junctions, hemichannels," in Neuroglia, 3rd Edn, eds H. Kettenmann and B. R. Ransom (Oxford: Oxford University Press), 292-305.

Retamal, M. A., Froger, N., Palacios-Prado, N., Ezan, P., Sáez, P. J., Sáez, J. C., et al. (2007). Cx43 Hemichannels and Gap Junction Channels in astrocytes are regulated oppositely by proinflammatory cytokines released from activate microglia. J. Neurosci. 27, 13781-13792. doi: 10.1523/JNEUROSCI.204207.2007
Sanacora, G., and Banasr, M. (2013). From pathophysiology to novel antidepressant drugs: glial contributions to the pathology and treatment of mood disorders. Biol. Psychiatry 73, 1172-1179. doi: 10.1016/j.biopsych.2013.03.032

Seidel, A., Arolt, V., Hunstiger, M., Rink, L., Behnisch, A., and Kirchner, H. (1995). Cytokine production and serum proteins in depression. Scand. J. Immunol. 41, 534-538. doi: 10.1111/j.1365-3083.1995.tb03604.x

Sluzewska, A., Rybakowski, J., Bosmans, E., Sobieska, M., Berghmans, R., Maes, M., et al. (1996). Indicators of immune activation in major depression. Psychiatry Res. 64, 161-167. doi: 10.1016/S0165-1781(96)02783-7

Stehberg, J., Moraga-Amaro, R., Salazar, C., Becerra, A., Echeverría, C., Orellana, J. A., et al. (2012). Release of gliotransmitters through astroglial connexin 43 hemichannels is necessary for fear memory consolidation in the basolateral amygdala. FASEB J. 26, 3649-3657. doi: 10.1096/fj.11-198416

Sun, J. D., Liu, Y., Yuan, Y. H., Li, J., and Chen, N. H. (2012). Gap junction dysfunction in the prefrontal cortex induces depressive-like behaviors in rats. Neuropsychopharmacology 37, 1305-1320. doi: 10.1038/npp.2011.319

Tai, Y. H., Tsai, R. Y., Lin, S. L., Yeh, C. C., Wang, J. J., Tao, P. L., et al. (2009). Amitriptyline suppresses neuroinflammation-dependent interleukin10-p38 mitogen-activated protein kinase-heme oxygenase-1 signaling pathway in chronic morphine-infused rats. Anesthesiology 110, 1379-1389. doi: 10.1097/ALN.0b013e31819fccd5

Takeuchi, H., and Suzumura, A. (2014). Gap junctions and hemichannels composed of connexins: potential therapeutic targets for neurodegenerative diseases. Front. Cell. Neurosci. 8:189. doi: 10.3389/fncel.2014.00189

Tomaz, V. S., Cordeiro, R. C., Costa, A. M., de Lucena, D. F., Nobre Júnior, H. V., de Sousa, F. C., et al. (2014). Antidepressant-like effect of nitric oxide synthase inhibitors and sildenafil against lipopolysaccharideinduced depressive-like behavior in mice. Neuroscience 268, 236-246. doi: 10.1016/j.neuroscience.2014.03.025

Valera, E., Ubhi, K., Mante, M., Rockenstein, E., and Masliah, E. (2014). Antidepressants reduce neuroinflammatory responses and astroglial alphasynuclein accumulation in a transgenic mouse model of multiple system atrophy. Glia 62, 317-337. doi: 10.1002/glia.22610

Vardjan, N., Verkhratsky, A., and Zorec, R. (2015). Pathologic potential of astrocytic vesicle traffic: new targets to treat neurologic diseases? Cell Transplant. 24, 599-612. doi: 10.3727/096368915X687750

Verkhratsky, A., Rodríguez, J. J., and Parpura, V. (2012). Neurotransmitters and integration in neuronal-astroglial networks. Neurochem. Res. 37, 2326-2338. doi: 10.1007/s11064-012-0765-6

Ye, B., Shen, H., Zhang, J., Zhu, Y. G., Ransom, B. R., Chen, X. C., et al. (2015). Dual pathways mediate $\beta$-amyloid stimulated glutathione release from astrocytes. Glia 63, 2208-2219. doi: 10.1002/glia.22886

Ye, Z. C., Wyeth, M. S., Baltan-Tekkok, S., and Ransom, B. R. (2003). Functional hemichannels in astrocytes: a novel mechanism of glutamate release. J. Neurosci. 23, 3588-3596.

Yirmiya, R., Pollak, Y., Barak, O., Avitsur, R., Ovadia, H., Bette, M., et al. (2001). Effects of antidepressant drugs on the behavioral and physiological responses to lipopolysaccharide (LPS) in rodents. Neuropsychopharmacology 24, 531-544. doi: 10.1016/S0893-133X(00)00226-8

Conflict of Interest Statement: The authors declare that the research was conducted in the absence of any commercial or financial relationships that could be construed as a potential conflict of interest.

Copyright (๑ 2016 Jeanson, Pondaven, Ezan, Mouthon, Charvériat and Giaume. This is an open-access article distributed under the terms of the Creative Commons Attribution License (CC BY). The use, distribution or reproduction in other forums is permitted, provided the original author(s) or licensor are credited and that the original publication in this journal is cited, in accordance with accepted academic practice. No use, distribution or reproduction is permitted which does not comply with these terms. 